\title{
“THERE'S REALIZING, AND THEN THERE'S REALIZING": HOW SOCIAL SUPPORT CAN COUNTER GASLIGHTING OF WOMEN OF COLOR SCIENTISTS
}

\author{
Michelle A. Rodrigues, ${ }^{1,2,3, *}$ Ruby Mendenhall, ${ }^{4,5} \mathcal{E}$ \\ Kathryn B.H. Clancy, \\ ${ }^{1}$ Department of Anthropology, University of Illinois at Urbana-Champaign, \\ Urbana-Champaign, Illinois, USA \\ ${ }^{2}$ Beckman Institute for Science and Technology, University of Illinois at \\ Urbana-Champaign, Urbana, Illinois, USA \\ ${ }^{3}$ Department of Social and Cultural Sciences, Marquette University, Milwaukee, \\ Wisconsin, USA \\ ${ }^{4}$ Department of Sociology and African-American Studies, University of Illinois at \\ Urbana-Champaign, Urbana, Illinois, USA \\ ${ }^{5}$ Carle Illinois College of Medicine, University of Illinois at Urbana-Champaign, \\ Champaign, Illinois, USA
}

*Address all correspondence to: Michelle A. Rodrigues, Lalumiere Hall 340, 1310 W. Clybourn St., Milwaukee WI 53233; Tel.: + 414-288-6838, E-mail: michelle.rodrigues@marquette.edu

The lack of minority representation within academic science means that women of color are often isolated from each other. Isolation limits women of color's ability to form supportive networks to deal with the stressors that result from bias and discrimination. Isolation can also prevent women of color from creating support networks that may buffer against stressors. We used a grounded approach to explore the extent to which being the "only" woman of color, versus one of a few, mediates the experiences of incivility, harassment, and broader discriminatory practices experienced by science faculty across rank. We ran six focus groups with a total of 15 women of color science faculty at a research-intensive Midwestern university to explore these themes. Our research supports previous findings that women of color of all ranks experience negative workplace experiences such as incivility and harassment, and the exclusion of women of color occurs at both institutional and interpersonal levels. Our findings yielded new insights into how experiences of social isolation lead to the internalization of gaslighting messages that deny or minimize the occurrence of incivility and harassment. We also found that social support helps women to contextualize their experiences, allowing them to recognize and identify it within the broader cultural patterns of sexism and racism. Social exclusion and isolation intensify the negative psychological impact of negative workplace experiences, whereas social support validates women of color's negative experiences and helps externalize these events. Therefore, we suggest that the level of isolation experienced by women of color faculty can mediate the relationship between negative experiences in academic science and personal and professional outcomes such as mental health and productivity. We use this model of psychological impacts of incivility and harassment to suggest future areas of research regarding women of color in STEM.

KEY WORDS: social support, women of color, incivilities, STEM, harassment 


\section{INTRODUCTION}

There is a push to increase the number of women in science (Armstrong and Jovanovic, 2015; Settles et al., 2006). However, initiatives focused on improving the representation of women in science often end up improving circumstances only for white women (Armstrong and Jovanovic, 2015; National Science Board [NSB], 2012). In recent years the number of white women in science has increased, but the number of women of color, particularly underrepresented minorities such as African Americans/Blacks, Latinas, and American Indians/Native Americans has decreased (Armstrong and Jovanovic, 2015; NSB, 2012; Rios and Stewart, 2015).

Such initiatives often focus on recruitment of girls and young women without addressing the factors that push women out of science. Women who pursue scientific careers face increased pressures due to bias, overt discrimination, and harassment (Aycock et al., 2019; Clancy et al., 2014; Cortina et al., 2001; Kabat-Farr and Cortina, 2012; Lewis et al., 2016; Moss-Racusin et al., 2012; Settles et al., 2006). For women of color, these pressures are intensified by intersecting forms of discrimination (Armstrong and Jovanovic, 2015; Clancy et al., 2017; Settles et al., 2006). These pressures discourage and push women of color out of academic careers, even when they demonstrate talent and achievement.

Social support can help people cope with hostile work environments. "Talking to a colleague" is the most common response when an employee experiences incivilities, or rude behaviors of ambiguous intent (Andersson and Pearson, 1999; Cortina and Magley, 2009; Cortina et al., 2001). The options for many women of color to talk to a colleague may be sparse or unhelpful. Women of color are often isolated in their workplaces, which may limit options to find colleagues with shared lived experiences, or form support networks. The lack of shared experiences with colleagues with majority identities may create a context that increases the likelihood of gaslighting, in which others minimize or deny one's experiences. Gaslighting can happen to such a degree that women of color may become uncertain about how to categorize their perceptions of negative workplace experiences (Berenstain, 2016).

While incivilities and some forms of harassment may seem minor in isolation, repeated incivility and harassment have negative mental and physical consequences (Buchanan and Fitzgerald, 2008; Cortina et al., 2001; Harrell, 2000; Huynh, 2012; Kabat-Farr and Cortina, 2012; Lim et al., 2008; Miner-Rubino and Cortina, 2004). In addition to decreased mental and physical health, negative workplace experiences have direct negative effects on career progress and productivity (Clancy et al., 2017; Hollis, 2017; Hutton and Gates, 2008; Kabat-Farr and Cortina, 2012; Lim and Cortina, 2005; Lim et al., 2008; Nelson et al., 2017; Riskin et al., 2015; Settles et al., 2006). Such negative experiences are common to women of color across many workplaces such as industry, health, and STEM fields (Buchanan and Fitzgerald, 2008; Kabat-Farr and Cortina, 2012). However, colleagues may cause harm in pervasive, culturally specific ways due to the masculine cultural context and entrenched hierarchies of academic science (Armstrong and Jovanovic, 2015; Bejerano and Bartosh, 2015; Berdahl et al., 
2018; Clancy et al., 2017; National Academies of Sciences, Engineering, and Medicine [NASEM], 2018). In academia, white women in the sciences are more likely to achieve higher ranks, and wield greater influence within their departments compared to women of color (Settles et al., 2006). Women of color often feel unsafe in the workplace and can miss out on professional opportunities as a result (Clancy et al., 2017). For graduate students and junior faculty, high rates of workplace harassment and a lack of institutional consequences for such behaviors create conditions that cause women of color to leave academia (Hollis, 2017).

For this study, we ran six focus groups of women of color science faculty at a large, research-intensive, predominantly white university to examine the dynamics of workplace incivility and harassment and isolation/social support in women of color scientists. Our research questions were: (1) How do workplace incivility and harassment vary with faculty rank and identity? (2) Are women of color in academic science able to access social support? (3) How are the experiences of workplace incivility and harassment mediated by degree of social exclusion/inclusion and thus access to social support? Based on previous studies, we expected that women of color would experience incivilities and harassment in their workplaces, and that isolation in the workplace would limit women of color's ability to seek social support. Faculty rank, racial identity, and gender identity may mediate these experiences, as these are different, but interrelated, axes related to power and marginality (Crenshaw, 1989; Kabat-Farr and Cortina, 2012). We used a modified grounded theory approach (Charmaz, 1996) to explore participants' perceptions of how social support attenuates the relationships between negative experiences and how participants understood and contextualize them. This approach was chosen over other methods for several reasons: (1) to develop new theoretical frameworks that listen to and are drawn from the lived experiences of participants; (2) to understand the processes by which the dynamics of incivility and harassment, in conjunction with social inclusion/exclusion, impact women of color in academic science; and (3) to develop conceptual models to describe these processes and possible solutions.

Based on our thematic analysis, we propose a model in which (1) negative workplace experiences among female scientists of color are mediated by rank, where higher frequency and more severe experiences are found among those of the lowest ranks, and (2) the degree of exclusion (depending on availability of social support networks) influences the extent to which women of color internalize negative experiences (Fig. 1).

\section{METHODS}

\subsection{Researcher Positionality}

Michelle Rodrigues is a cisgender, Asian American woman. Her parents immigrated to the United States from Bombay/Mumbai, India, and she was born in Chicago and raised in the Chicago suburbs. Her family is from the East Indian Catholic community, an ethno-religious community shaped by waves of Portuguese and British colonization of the western Indian coast. Her interest in studying friendship and social coping mecha- 


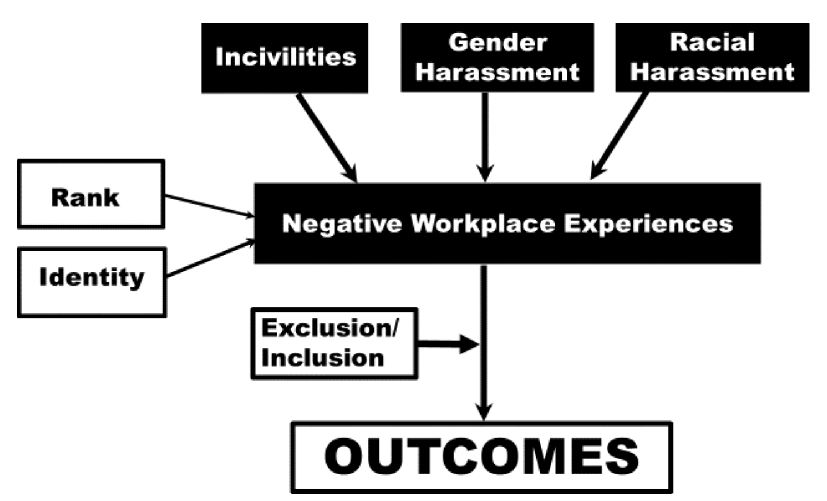

FIG. 1: Proposed model. Rank and identity influence severity of negative workplace and experiences, while degree of exclusion versus inclusion mediate how those experiences affect individual career and health outcomes.

nisms draws from her appreciation for the supportive friendship networks in her life, and her interest in the intersection of racial and gender oppression are shaped by experiences as a field primatologist and biological anthropologist.

Ruby Mendenhall is a cis, heterosexual African American woman who was raised by parents who migrated to Chicago from Macon, Mississippi (mother) and Camden, Alabama (father). During her childhood, she spent summers in Camden, Alabama with her grandparents and extended family. These summer experiences influenced her interest in capturing Black cultural wealth that is often hidden. She was raised in Chicago in a Black segregated neighborhood with a strong sense of community. She started studying racial microaggressions (RMAs) in 2007, shortly after arriving at the University of Illinois. RMAs research and other experiences highlight the critical need to understand faculty's experiences on campus and to ensure that all barriers to higher education are eliminated.

Kathryn Clancy is a cisgender, queer, white woman from New England. She is married to a man and is a mother to two daughters. Clancy is an Associate Professor of Anthropology at the University of Illinois, and studies reproductive justice with a focus on understanding the environmental stressors that influence the menstrual cycle. Much of her recent work has focused on intersecting psychosocial stressors such as sexual harassment, racial harassment, and LGBTQ harassment, particularly in academic STEM settings.

\subsection{Statement of Protection of Marginalized Populations}

To protect participants that are members of marginalized populations, we held focus groups for each rank separately, and ensured that no two members of the same department were in the same group. To protect their identities, we do not disclose racial/ethnic group of individual participants, nor do we use any identifying features of participant identity beyond rank. 


\subsection{Data Collection}

We conducted focus groups with science faculty at a large, predominantly white, research-intensive university in the Midwest. We recruited women of color from the academic science faculty, broadly setting inclusion criteria as (1) faculty in the social, natural, and physical sciences, including engineering, and (2) participants who self-identify as women of color. Participants were recruited via e-mails sent out to unit heads, listservs, and faculty. Participants were offered entry into a lottery for one of three \$25 Amazon gift cards. We conducted a total of six focus groups with nontenure-track (2), tenure-track (3), and tenured faculty (1) (Table 1). Each focus group contained two to three participants not within the same department. Fifteen faculty members participated.

The number of focus groups we conducted is consistent with the methodological norm of 4-6 focus groups (Morgan, 1996). The number of participants in our study is lower than the typical range of 6-8 participants (Rabiee, 2004). The primary reason for the small number of participants per group was the small number of already-overburdened female science faculty of color. However, smaller focus groups are often more appropriate when dealing with emotionally sensitive information, and when participants are from marginalized populations (Morgan, 1996; Rabiee, 2004). Thus, the smaller group size was advantageous in providing participants with ample time to discuss their experiences. The small group size also allowed for group-centered social interactions and opportunity to co-construct meaning (Madriz, 2000; Wilkinson, 1998). All participants spoke several times and facilitators ensured various viewpoints were able to be expressed. Participants were from the social, natural, and physical sciences, and included individuals of Black/African American, East Asian, South Asian, and Latina backgrounds. In order to protect participants' identities, we do not disclose the breakdown of participants in each racial/ethnic group.

Focus groups were scheduled for 1.5 hours and included one to two interviewers (KBHC and MAR). During the focus groups, one interviewer led the focus group, while the second served primarily as a notetaker and observer. Because KBHC had previous experience with interviews and focus groups, she led the first two focus groups while

TABLE 1: Composition of focus groups. The interviewer listed first was responsible for leading the focus group, while the second served primarily as a note taker and observer

\begin{tabular}{lccc}
\hline Focus group & Rank & Participants & Interviewers \\
\hline 1 & Assistant professors & 3 & KBHC, MAR \\
\hline 2 & Assistant professors & 3 & KBHC, MAR \\
\hline 3 & Non-tenure-track & 2 & MAR, KBHC \\
\hline 4 & Non-tenure-track & 2 & MAR, KBHC \\
\hline 5 & Assistant professors & 2 & MAR, KBHC \\
\hline 6 & Tenured professors & 3 & MAR \\
\hline
\end{tabular}

Volume 27, Issue 2, 2021 
MAR observed. MAR led the subsequent four focus groups. All participants were informed of consent procedures and signed consent forms before beginning the focus group questions. After obtaining informed consent, we gave participants the option to choose a pseudonym. Then, we began recording and asked questions in a semistructured format (see Table 2).

\subsection{Data Analysis}

We used a modified grounded theory approach incorporating thematic analysis (Braun and Clarke, 2006; Charmaz, 1996; Malagon et al., 2009). We chose to use a grounded theory approach to elucidate themes that emerged from focus group participants themselves (Charmaz, 1996; Malagon et al., 2009). This methodological approach is valuable when conducting research with marginalized participants from the lens of critical race theory, in order to ensure that the research findings reflect their lived experiences rather than the researchers' preconceptions (Malagon et al., 2009). Furthermore, the

TABLE 2: Semistructured focus group questions

\section{Focus group questions}

How would you characterize your workplace experiences within your department?

Within the broader university community?

What supportive interactions have you had with colleagues in your department?

Do you have colleagues within your department or within the university that you consider friends?

Do you have colleagues you feel you can rely on for support when dealing with workplace stressors?

How often do you feel you have disrespectful interactions with people at work?

Are there any particular workplace incidences, good or bad, that you would like to share? Examples: experiences in departmental meetings, service committees, informal interactions with colleagues, interactions with undergraduate and graduate students.

What sort of personal support structure did you have to deal with negative interactions? Did you discuss it with colleagues, or friends outside of the workplace?

Do you think your identity (e.g. gender, gender identity, race, ethnicity, sexuality, disability status) has influenced your experience in academia? Why or why not? Do you feel there is any aspect of your identity that isolates you compared to colleagues?

How has the climate of your workplace contributed to your experience at the university? Do you consider it to be an overall positive or negative climate?

Has your career or productivity been influenced in any way by your workplace experiences? In what way has your productivity improved or suffered? Can you provide some examples?

Is the university community an inclusive place to you? If so, how? If not, what do you think it will take to make it more inclusive?

Is there anything else you would like to tell me today? 
grounded theory approach was most appropriate for our goals in developing models to describe the processes by which social experiences affected participants. During each session, we took individual notes, and discussed emergent themes. However, we did not begin coding interview transcripts until after the focus groups were completed, due to the time required for transcription. Audio recordings of the focus groups were transcribed verbatim by the transcription company Landmark Associates. We analyzed the focus group transcripts via thematic analysis, which looks for patterns in the data associated with the phenomena being studied (Braun and Clarke, 2006). Using the initial notes taken during the focus groups to guide in identifying potential themes, MAR and $\mathrm{KBHC}$ read through the focus group transcripts. We each took notes on salient points that emerged during the focus groups, and then did initial readings through the focus group transcripts to identify common themes and then a second reading to conduct line-by-line coding.

After our initial readings, we met to discuss these themes, and identified an initial set of six; we then reread through the transcripts using focused coding to identify instances of each theme. Through multiple readings and discussion, we settled on three major themes: (1) the incidence of negative workplace experiences, (2) experiences of social support versus social exclusion, and (3) the role of uncertainty in ascribing meaning to these experiences (i.e., "I don't know if it's my race, gender, or something else"). There is some overlap between negative workplace experiences and exclusion, as workplace incivilities include exclusion from professional comradery (Cortina et al., 2001). However, our coding of social support versus exclusion was defined more broadly, to incorporate instances of both positive social support as well as absence of support or feelings of isolation and exclusion in both personal and professional contexts. Within the first theme, we (MAR and KBHC) each then recoded half the transcripts to identify three types of negative workplace experiences: (1) incivility, (2) gender harassment, and (3) racial harassment (Table $3)$. After comparing and discussing differences in interobserver coding, we then switched to recode each other's focus groups. We discussed any differences in our coding, specifically discussing places where our coding disagreed. Our only challenge was reaching concordance in defining "incivilities," particularly describing discrete incidences of them. Once we recoded, taking care to not re-count the same story brought up multiple times, our coding results were nearly identical. Coding around social support, exclusion, and feelings of uncertainty were all highly concordant.

\section{RESULTS AND DISCUSSION}

\subsection{Women of Color Experience Significant Interpersonal and Structural Oppressions at Work}

There are at least three types of negative workplace experiences to which women of color in the sciences are particularly vulnerable: incivilities, sexual harassment, and 
TABLE 3: Definitions and examples of negative workplace experiences

\begin{tabular}{|c|c|c|}
\hline Experience & Definition & Example \\
\hline Incivility & $\begin{array}{l}\text { Inconsiderate or rude behavior } \\
\text { with ambiguous intent, including } \\
\text { condescending or derogatory remarks, } \\
\text { unprofessional behavior, or exclusion } \\
\text { from professional comradery (derived } \\
\text { from Andersson and Pearson, 1999; } \\
\text { Cortina et al., 2001). }\end{array}$ & $\begin{array}{l}\text { "I go to shake her hand, and she } \\
\text { totally just-she sees me. There's } \\
\text { no way you could miss that I'm } \\
\text { going to shake her hand. She } \\
\text { turns to the developer and is like } \\
\text { 'oh, I've heard such good things } \\
\text { about you,'and shakes his hand. } \\
\text { Then, she shakes my hand, and } \\
\text { doesn't even look at me." }\end{array}$ \\
\hline $\begin{array}{l}\text { Gender } \\
\text { harassment }\end{array}$ & $\begin{array}{l}\text { Hostile treatment or differential } \\
\text { treatment based on derogatory } \\
\text { attitudes toward women, including } \\
\text { "put-downs" or negative jokes } \\
\text { and commentary based on gender } \\
\text { stereotypes (derived from Leskinen et } \\
\text { al., 2011). }\end{array}$ & $\begin{array}{l}\text { "I feel like if I present myself } \\
\text { as really feminine...it triggers } \\
\text { the idea in the men's mind that } \\
\text { they can do things with me that } \\
\text { they would not do with a male } \\
\text { colleague, like kiss me on the } \\
\text { cheek and conferences and } \\
\text { things." }\end{array}$ \\
\hline $\begin{array}{l}\text { Racial } \\
\text { harassment }\end{array}$ & $\begin{array}{l}\text { Hostile or differential treatment based } \\
\text { on race or ethnicity, including verbal } \\
\text { harassment such as slurs, ethnic jokes, } \\
\text { or derogatory comments, denial of } \\
\text { racism, or social exclusion based } \\
\text { on race or ethnicity (derived from } \\
\text { Buchanan and Fitzgerald, 2008). }\end{array}$ & $\begin{array}{l}\text { "A faculty member basically asks } \\
\text { a question of essentially does } \\
\text { race even—is race still even a } \\
\text { problem? I don't see it being a } \\
\text { problem, etc." }\end{array}$ \\
\hline
\end{tabular}

racial harassment (Fig. 1, Table 3). In our sample, incivilities were by far the most pervasive negative workplace experience. As one tenure-track respondent shared how her expertise was questioned:

I've had a student challenge my method, challenge material, challenge my grading scheme.... I've had a graduate student question my credentials, question my methods. Asked me if I knew how to advise a project. Even I had a colleague challenge my work.

The questioning of this participant's credentials is one type of incivility that reminds women of color that those students and colleagues doubt whether they belong. Interview respondents described a workplace where they experienced incivilities from all directions, and their ability to navigate these experiences varied with rank. Non-tenure-track faculty tied these experiences to the precarity of their jobs, whereas tenure-track faculty endured them for the sake of tenure. Tenured faculty, while sometimes more protected in their current positions, reflected on the years of exclusion they endured as junior fac- 
ulty, and how it restricted the trajectory of their careers. As one tenured professor shared regarding her experience with professional exclusion:

[The impact of exclusion] has taken me like close to eight years to figure...out because I know how to in some ways navigate. I know how to get grants. I know how to write papers and I know how to run my lab. What I'm not getting is anybody asking me to give a keynote speech. I'm not getting somebody asking me to work on this committee.... That's all that works [in my unit]... let me tell you.

This participant's comments highlight the ways in which women of color scientists are competent in doing their work but are hindered by both a lack of recognition for their accomplishments, and exclusion from campus and professional networks.

Sexual harassment can include "come-ons" and "put-downs," (Leskinen et al., 2011; Table 3). Put-downs, which include sexist hostility, crude behavior, and professional sabotage, represent most of the sexual harassment that takes place, particularly in male-dominated fields (Aycock et al., 2019; Leskinen et al., 2011). Respondents identified some of the mistreatment they experienced in the workplace as gendered and sexist, but not sexual. As one respondent reflected:

Then there's a lot of other-being a woman and being in this [non-tenure-track] role, and then you're basically everybody's secretary even though they don't wanna say that. I was really almost kind of the work wife of this really famous scientist, but there was enough positives that I ignored that part. You know what I'm saying? There's a lot of disrespect with being a woman in science, I think. In the hard sciences. It's just all subtle.... I have a ton of incidents if you wanna hear about the sexism. I wanna write a book.

When respondents felt their negative workplace experience was a result of their identity groups, they often first identified the gendered nature of the harassment (e.g., "because I'm a woman"), and then how it was related to gendered-racial identity (e.g., "because I'm an Asian woman") or racial identity (e.g., "because I am Black").

Racial harassment is hostile or differential treatment based on race or ethnicity, which can include verbal harassment such as slurs and ethnic jokes, derogatory comments, or social exclusion based on race or ethnicity (Buchanan and Fitzgerald, 2008; Table 3). Many people "know" they are not supposed to hold racist beliefs, so the way they manifest racist behavior is through selective forms of exclusion (Cortina et al., 2013; Deitch et al., 2003; Hebl et al., 2008; Kabat-Farr and Cortina, 2012). As with incivilities and sexual harassment, racial harassment's more nebulous forms may not seem severe, but are psychologically distressful (Buchanan and Fitzgerald, 2008; Buchanan et al., 2008). Many of these behaviors and attitudes seemed to be exclusionary or to make respondents feel unwelcome, but rarely were tied to anything particular they had done. Furthermore, although tenure-track faculty and non-tenure-track faculty experience in-

Volume 27, Issue 2, 2021 
civility and harassment at similar levels of frequency, non-tenure-track faculty reported more severe experiences.

\subsection{Women of Color Experience Gaslighting from Colleagues}

White allies are individuals who recognize the existence of white privilege, and are committed to leveraging their privilege in order to interrupt racism and promote equity (Spanierman and Smith, 2017). White allies can advocate for those they mentor, and they can interrupt instances of racism or sexism. However, white allyship can also take the form of surface allyship focused on maintaining an inclusive appearance instead of attempting genuine structural change (Spanierman and Smith, 2017). Another potential pitfall that can undermine minority faculty success is when white allies engage in paternalistic behavior toward racialized minorities. White allies may be unaware of how their lived experiences are different from the people of color with whom they purport allyship. This lack of racial awareness can lead to the dismissal of people of color's perspectives, misdirected advice, or an inability to understand the barriers people of color face in the workplace.

In our focus groups, participants described some white allies who were genuinely helpful when they intervened to support them. However, participants most often noted surface allyship from their white mentors and white allies. Often, mentors and colleagues had constructive intentions, but their misdirected efforts resulted in further marginalization.

In cases when white colleagues and mentors did interrupt negative experiences, they reduced the severity of the situation and prevented it from escalating. For example, one tenure-track professor described an intervention she witnessed:

A faculty member basically asks a question of essentially, does race even-is race still even a problem? I don't see it being a problem, etc. As I'm staring at him open-mouthed trying to figure out what to say, another faculty member turned to him and said, 'Well, that's all well and good until your children come home saying kids won 't play with them 'cause they're not white enough, 'cause those kids happen to be mixed race.' That was another white faculty, a much more senior white faculty member.

This participant highlights how bystanders can provide genuine allyship by calling attention to problematic statements. In this case, when the participant was gaslit by a faculty member who was denying the existence of racism, the white senior ally reminded him, and by extension, everyone else in the room, that racism was still a real problem that harms racialized minorities. While these experiences were beneficial, they were rare in our sample. Instead, the majority of women of color faculty experienced a combination of surface allyship and gaslighting. Often, surface allyship came from challenges in mentoring relationships, in which mentors did not give critical feedback, were paternalistic, or failed to account for how their own experiences differed from the women they were mentoring. Being one or one of a few faculty of color in a department increases the mental load for women of color science faculty through the extra emo- 
tional labor needed to manage their relationships with their white colleagues and meet the emotional needs of more junior faculty and students of color. This mental labor is exacerbated for women of color when they experience gaslighting.

Gaslighting is when another person denies the external realities you are experiencing, causing you to doubt your own perceptions (Berenstain, 2016). For women of color, this takes the form of colleagues doubting or outright denying their negative experiences. This denial further marginalizes women of color (Berenstain, 2016; Fatima, 2017). Participants in our sample reported experiences of gaslighting in which colleagues tried to minimize their experiences. As an example, one tenure-track participant recounted collegial gaslighting in response to an incident of racial harassment:

There is that incident [someone] ended up with a [racist symbol] left on their desk by a colleague in their office .... They're like, 'Well, there's idiots everywhere. You just have to put your head down and not worry about it.' I'm like, 'I can't not worry about it.' I feel threatened right now. I feel at risk right now. I feel like I don't feel safe right now. No one was recognizing that fact. That I think was probably the biggest [issue]. It [advice] was well-intentioned. I think people are just like, 'oh, it's no big deal, there's idiots everywhere. 'It's like, but those idiots aren't trying to kill you.

The participant's colleague may have been trying to reassure her. However, the minimizing nature of their remark was a form of gaslighting that denied the risk that this threat posed. It came from the white colleague's perspective of not accurately perceiving the magnitude of the racist symbol in threatening the safety of marginalized staff. When women of color faculty are told to ignore racist or sexist acts, or when they are not addressed publicly, it sends a chilling message to faculty of color that their safety or well-being is not a priority.

Participants also described how departmental initiatives toward diversity and inclusion created an environment of gaslighting. Participants recounted situations in which initiatives did not include marginalized students or faculty in their planning or presented a disingenuous façade. The result was a hollow message of inclusion that countered participants' experiences and intensified feelings of marginalization. One tenure-track participant explained her frustration at hollow diversity initiatives:

They wanna do things. I think it makes them feel better to do things, instead of to actually do-instead of having hard conversations, about, 'Are we actually welcoming? Why do we have so few students of color?'

Such diversity initiatives that are led by white faculty and staff center white colleagues' desire to present a rosy picture of inclusion, while they continue to avoid uncomfortable conversations about the negative experiences of faculty of color. Such initiatives serve to gaslight marginalized students and faculty, as they are perpetually told the environment is welcoming and inclusive while their own lived experiences are ignored and denied.

Volume 27, Issue 2, 2021 
Women of color within academic environments often experience a tension between hypervisibility and invisibility (Lewis et al., 2016; Navarro et al., 2013), though the women in our sample tended to report invisibility. One tenure-track participant explained how it felt to be the only minority woman in a conversation about diversity:

[I]t is really amplified by the fact that I'm one of the only [people of color]. So-especially like I said, so much of it's not directed directly at me. It's in these conversations that [racial comments] are had. For example, when we're discussing diversity initiatives for the department [and] people start talking about, 'We can't lower our standards.'

The presumption in this statement is that excellence and minority status are mutually exclusive in a job candidate. The participant's colleagues render her excellence invisible despite her success as a woman of color scientist. As another tenure-track respondent pointed out, colleagues would make negative statements about her racial/ethnic group:

Again, it's just like-it's basically those times when I feel like not asserting my identity in a situation is important, because obviously there 's-you're assuming that I am just like you. I feel like I get-what's the word I'm looking for? That kind of erasure. What do you call it when someone's assuming that when they're talking with you, discussing with you, they're just assuming that you're just like them. Then they just start telling you things. You're like, 'Okay. You just apparently forgot that I'm Black, and you're saying all this stuff about Black people.

That's not okay.'

These colleagues were empowered to make derogatory statements because they assumed her ability to assimilate to white academic norms meant she was distanced from kinship with her own racial/ethnic group. Thus, they could make insulting comments about her ethnicity, while assuring themselves of plausible deniability because they perceived her as "not like the others." On many college campuses, both the administration and faculty assert the values of inclusivity, while continuing to reinforce beliefs about meritocracy in their culture and climate (NASEM, 2018). The mismatch between institutional messaging and women of color's experiences are compounded by being gaslit by colleagues and how that leads to feelings of uncertainty regarding causation. These experiences tells women of color that they do not belong, and that their intellectual and academic prowess is insufficient for their success (Lewis et al., 2016).

\subsection{Social Support Mediates the Extent to Which Respondents Externalize or Internalize Their Negative Experiences}

Our first model (Fig. 1) proposes that degree of social inclusion versus exclusion would mediate the impact of negative workplace experiences on health and productivity outcomes. Drawing from the psychological processes of anxiety versus validation described 
by participants, we created a second model, illustrating how experiences of isolation versus social support mediates how women of color are affected by negative workplace experiences based on their access to supportive networks (Fig. 2).

One of the challenges with occupying dimensions of marginalized identities is that experiences related to each of these identities cannot be easily parsed out due to intersecting systems of oppressions (Crenshaw, 1989). Women of color experience challenges related to their dual marginality, and reactions to each facet of those identities occur simultaneously (Ko et al., 2014). Across the focus groups, an emergent theme was the expression of uncertainty regarding how identity affected their experiences. Participants knew their identity might affect their interactions but were uncertain if they should attribute experiences to their identity versus other causes, such as their own worth or belonging as a scientist. For example, one tenure-track participant described the tensions of experiencing overlapping oppressions based on gender, race, and age, and trying to parse the cause:

Sometimes as I navigate various different, I guess, arenas within campus, I do have a similar thing of not knowing. Are you reacting to me because I'm a woman? Because I'm, like I said, a person of color? Is it because of my age and that I look like I'm a student .... I feel triangulated, if I were to use a clinical term.

This participant's use of the word "triangulated" highlights the tension in those intersecting axes of oppression. It further highlights the way this lack of knowing results in a struggle to identify if negative experiences are due to how their identity is perceived versus due to their worth as a scientist.

Many participants reported a sense of attributional ambiguity, in which they are uncertain if negative treatment was identity-based, or from other causes (Fatima, 2017; Schneider et al., 2000; Sue et al., 2007). Participants described difficulty in determining what facets of identity, if any, were the salient causes of negative experiences, and this difficulty created a heightened sense of anxiety. For example, a non-tenure-track respondent described a similar sense of attributional anxiety in trying to ascertain the causes of hostile treatment:

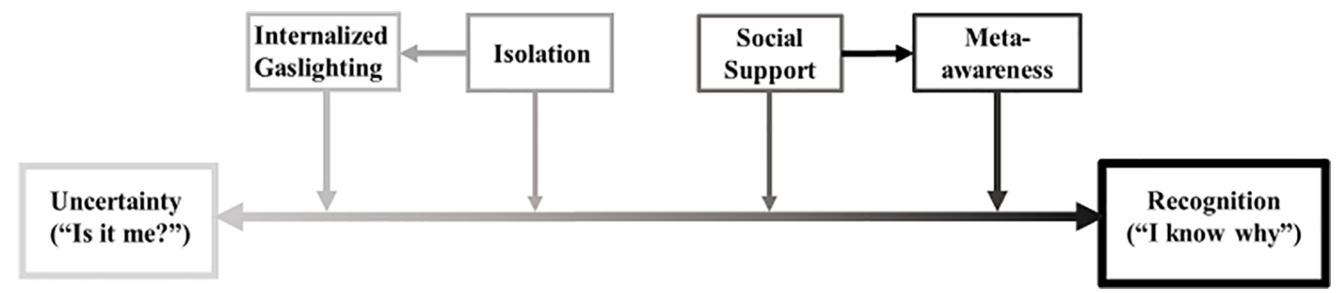

FIG. 2: The continuum from uncertainty to recognition. Social exclusion versus inclusion (social support) influence how individuals interpret the causes of negative workplace experiences.

Volume 27, Issue 2, 2021 
They just were so angry at me for no reason. At least I couldn't think, just like you said, maybe things you cannot prove. Yeah. Maybe they think, 'They can't be treating you like this because you are a woman, and Asian, and you look likethere's no bigger guy behind you. 'Even so, I just don 't understand it. There's no need to be rude. Unless I did something to them, there's no reason.

As a non-tenure-track faculty member, this participant was subject to escalated levels of hostility, which she attributed to the intersection of gender, race, and rank. However, her confidence in knowing the cause was tempered by the frustration that the perpetrator had plausible deniability. Even when women may suspect these experiences are related to identity, their ambiguity may make it difficult to ascertain why these experiences continue to occur or demonstrate it to others. However, experiences of social support are essential in providing the necessary context to interpret these negative workplace experiences. Social isolation compounded feelings of attributional anxiety, in which women worry over whether they are correctly interpreting the causes of negative treatment, while social support provided the necessary context to externalize negative workplace experiences within broader cultural patterns (Fig. 2).

\subsubsection{Isolation Exacerbates Attributional Anxiety: "Is It Me?"}

Consistent with the literature, many participants reported feeling isolated and excluded, particularly if they were the "only" woman of color in their department. Many discussions of social support focus on the emotional aspect of support. However, social support includes instrumental support, such as providing direct assistance, sharing resources, or exchanging favors (Gunnar, 2017; Morrison, 2009). However, the emotional and instrumental sources of social support can be intertwined; in particular, exclusion from social networks may compound feelings of isolation and cut individuals off from access to emotional support. Social networks are an essential part of academic productivity, as collaborative relationships are typically forged within small, clustered communities (Newman, 2001). Inclusion within these networks facilitates access to develop collaborative grants and publications, as well as acknowledgement and recognition for achievements. One tenured participant described the negative impact that exclusion from larger academic networks had on her ability to get grants:

If you're not part of their social circle, then it [professional advancement] becomes quite different. They are doing this together. They're putting each other on grants for no reason and [even] if [their research areas] are completely different, just so that they could help each other out and that happens a lot too. I think that we get left out and I realized that after like five years.

Such exclusion from insider circles resulted in the participant having to work harder to apply for grants alone, while colleagues with insider status were added to proposals without earning those distinctions. Another common theme among participants' experi- 
ences is the lack of acknowledgement they felt by their departments, or exclusion from the "in-crowd." For example, one tenured professor described the lack of acknowledgement from her department even though she was valued elsewhere:

I won a number of outside [awards]-they were grants but there was also very prestigious like kind of postdoctoral type things and other things that kind of singled me out nationally, and I still didn't get put up for the campus award as an assistant professor. I had an outside offer from one of the most sought-after universities in this nation and ...it does make you wonder. You're like, 'Okay, so what do I have to do to be good in my department?'

This lack of acknowledgement contributed to her anxiety by causing the participant to question what more she must do to earn the respect of her department, when the problem is likely not her work, but rather the biases of her departmental leaders. Both tenure-track and tenured professors described the extra steps they had to take to build collaborative networks outside their department or university due to these experiences. One tenured professor explained:

There's the other part that you find you have to reach out to people who are outside the university. I feel like there's extra work I know I go through just to try to find contacts who kind of look like me, or who negotiate institutions like this.

The extra work required to build outside networks requires that women of color faculty put in a greater amount of work, while earning less professional respect and recognition compared to their white colleagues. This mismatch between work effort, accomplishment, and recognition may lead scientists with these experiences to further question whether they belong, or if there is something wrong with the work they are doing.

When women are isolated, collegial gaslighting can become internalized, as women wonder, "Is it me?" (Fig. 2). Such internalized gaslighting intensifies feelings of imposter syndrome, as women internalize the external messages that they do not belong (Clance and Imes, 1978). This leads women to question whether they are genuinely experiencing incivility or harassment, whether they are overreacting to these experiences, or whether they did something to cause or deserve negative treatment. Such internalized gaslighting can increase anxiety, negative rumination, and amplify perceptions that they do not belong.

\subsubsection{Social Support Provides Context to Externalize Negative Experiences ("I Know Why")}

Social support mediated how participants processed feelings of uncertainty. When isolated, women of color had little access to emotional or instrumental support, and fewer options for getting accurate feedback to contextualize their experiences. Social support 
counteracts the process of internalized gaslighting by providing an opportunity to check those experiences against trusted colleagues' and friends' perceptions. When women have access to social support, colleagues and friends reaffirm that their experiences of incivility or harassment are real, that they are not overreacting to them, and that these experiences are not due to personal faults. This leads to meta-awareness, where women are able to recognize that their negative experiences are part of larger societal patterns of bias and discrimination. This recognition allows them to externalize those experiences, placing the locus of control on broader societal patterns rather than personal characteristics (Fig. 2).

One tenure-track participant explained the insight she had when talking to a colleague who had similar negative experiences with a colleague: "Hearing their experiences about that person, too, it's like, 'Whoa, it's not just me." Being able to check your thinking with a colleague after a troubling experience is incredibly helpful. Such social support can come from allies intervening and confirming that such behaviors are inappropriate, but support from other women of color is especially important in countering the pattern of self-gaslighting, in which women internalize harmful messages they have received from colleagues. Other women of color may be particularly able to empathize and reaffirm her interpretation of the experience, whereas white and/or male colleagues may not recognize the underlying patterns (Fatima, 2017). Such validation may be an extension of patterns that begin in adolescence, when racialized minorities in predominantly white environments seek validation from peers with similar racial backgrounds (Tatum, 2017).

One tenured professor highlighted how her students helped provide such validation:

Sometimes my doctoral students are the ones who are kind of like-they just help me do reality checks, right? They just kind of say, 'Yeah. That was a microaggression, 'or 'Yeah, I've noticed that like people just think they can call you by your first name. They don't do that in other classes that I know with those people, right?'

This participant's students served an important role in validating that she was being treated differently than white professors. Similarly, a tenure-track participant mentioned that scholarly literature provided a similar source of support, by documenting biases that validated that her experiences were part of a wider pattern. She explains:

It's hard for me to be able to explain my different experience. It's even harder, because most of the time, I'm thinking, 'Maybe it's just-maybe I'm-who am I to generalize my experience to everyone looking like me. Maybe it just happened to be me.'It's just happening, and this is for me what happens is I have to go back into the literature and just learn about what has been done and be able to-it reminds me of the patterns.

The documentation of these patterns in the literature provided the same affirmation as checking with supportive students or colleagues. Echoing this, a tenured professor 
described meta-awareness of her continuing understanding of how race and gender affect her experiences at work. This perspective allowed her to step back and recognize how her experiences fit into larger patterns of discrimination against minority women. She explained:

I think there's levels of realizing. It's realizing and then there's realizing and then there's realizing.

Such meta-awareness provides a means to mentally cope with negative experiences. Rather than internalizing the toxic workplace experiences, labeling the causes of discriminatory treatment places the locus of culpability outside of the self. One non-tenuretrack participant described this sense of recognition:

I absolutely do believe that if I were a white male, I would not be experiencing this. I believe that to my core. Or even a Black male [would not have these experiences]. I think being Black and female, a woman of color, has worked against me in this environment.

Such recognition is affirming, as she can confidently attribute the causes of negative treatment to discrimination. In some cases, hiring cohorts of women of color, and/or creating opportunities to network with other women of color faculty played an essential part of some participants' success in building supportive networks. One tenure-track professor explained this benefit:

I was hired at the same time as another Black woman in my school. That has actually made a big difference. Her experience has been very different from mine, but I'm really the person that she talks to about it. Anything that comes up, we can always talk to each other. I think it's a good decision that the school made- to hire us together.

The availability of such cohorts provides a built-in level of social support that often may be inaccessible to those without such a cohort. Participants varied in their access to social support both within and outside their workplace environments. Some had access to partners, family, or friendship networks outside of work, while others emphasized that their work limited the ability to find romantic partners and/or friendships. Several participants also emphasized that they found the community outside of the university isolating and mentioned reliance on friends or family that lived in other towns. For example, one non-tenure-track participant described coping with her isolation through long-distance relationships:

Most of all, I talk to friends. Most of my friends here, I had some, but my really, really long-term friends [are elsewhere].... We spend hours on the phone on weekends.

Volume 27, Issue 2, 2021 
Many participants recognized the need to seek social support, particularly when feeling overwhelmed by negative workplace experiences. One non-tenure-track participant highlighted the need to seek social support to deal with depression caused by toxic workplace experiences:

You have to be-try to survive, right? Otherwise, what do you do? You're either depressed from time to time, so you want to get out, right? Otherwise, what do you do? There's no other choice. Either you [commit] suicide or you kill someone, right? You don't want to go that way, so you talk to a friend to try to relieve that.

Her words point to a systemic problem, in which the accumulated trauma of negative workplace experiences and gaslighting can take a serious toll on health. Stressful social experiences can leave traces on the body, compromising mental and physical health (Brody et al., 2013; Geronimus et al., 2006; Gravlee, 2009; Sellers et al., 2003). While individual support-seeking can be an important strategy to cope with these traumas, they still place the burden of dealing with the impact of negative workplace experiences on the already-marginalized faculty. To solve this problem, we need institutional and cultural changes that can both foster the development of support networks and interrupt patterns of incivility and harassment.

\section{CONCLUSIONS AND RECOMMENDATIONS}

We found that women of color are often excluded from faculty networks and institutional recognition. Women of color faculty at all ranks face negative workplace experiences, which are most severe for non-tenure-track faculty. At times, colleagues' attempts at mentoring or support serve to further gaslight and marginalize women of color by denying their experiences. Finally, because women of color were often isolated, the absence of social support networks meant they had little recourse in contextualizing their racial and gender experiences.

Without sufficient social support, isolated faculty were more likely to internalize their colleagues' gaslighting and question their experience. Those faculty who did have adequate social support better contextualized and externalized their experience by recognizing that the fault lay with systemic and interpersonal oppression, not their own abilities. Our findings emphasize that creating an inclusive environment for women of color requires active sponsorship and intervention, including increasing access to supportive networks of women of color, for women of color.

Women of color science faculty in our sample faced the same negative workplace experiences detailed across several other samples (Berdahl and Moore, 2006; Buchanan and Fitzgerald, 2008; Clancy et al., 2017; Kabat-Farr and Cortina, 2012; Shupe et al., 2002): in particular, they faced frequent incivilities, sexual harassment, and racial harassment, particularly "put-downs." One limitation of our research that requires further exploration is how varying racial and ethnic identities, as well as how these identities are 
read by others, impact women of color's experiences. Different racial and ethnic groups can experience culturally specific forms of discrimination, such as the sexualized stereotypes and harassment that Black women experience (Buchanan et al., 2008; Lewis et al., 2016) versus model minority expectations of compliance and submission projected onto East Asian women (Ko et al., 2013; Rios and Stewart, 2015; Roshanravan, 2009).

We proposed that impact of negative workplace experiences would be mediated by social inclusion versus exclusion (Fig. 1), and we found that outcomes were exacerbated by the behaviors of colleagues, as well as participants' degree of isolation in conjunction with invisibility. Participants described the ways in which their social environmenttheir degree of isolation in their department, and their ability to commiserate with other women of color-influenced the consequences of negative workplace experiences. We illustrate this in our second model (Fig. 2). Degree of isolation versus social support affects how women of color contextualize negative workplace experiences. Supportive colleagues and students were able to provide the checks needed when facing unexpected and unwarranted incivilities. Without them, negative experiences were internalized, leading to participants wondering whether their worthiness, abilities, or other attributes were to blame. This was especially true for the non-tenure-track women of our sample, who were the most isolated and had the most severe negative workplace experiences.

The consequences of a continued hostile environment for women of color, coupled with performative, rather than substantive and sustained, diversity initiatives, are that academic science continues to lose important voices and scholarship from women of color in science. The participants of this sample, who were successful faculty scientists at a research-intensive institution, readily identified ways in which their careers had been curtailed, their contributions lessened, or that they were unable to bring their whole selves to their work. The environment for women of color science faculty can be one of hostility, compounded by being so few in number or with so few allies that offer help beyond surface allyship, that these scientists cannot offset the costs of a hostile environment with supportive social networks.

Although our results point to a hostile environment for women of color and patterns of exclusion and marginalization, they also point to solutions for improvement. Colleges and universities must make active efforts to improve the social environment for women of color by hiring cohorts of women of color, hiring women of color into positions of power for the purposes of role modeling and mentoring. While this is just one part of necessary multilevel efforts to deserving scholars of color, this step can start to make it possible for academic science departments to become places of transformational change, productivity, and inclusion.

\section{ACKNOWLEDGMENTS}

This research was funded by the Illinois Leadership Center Faculty Fellowship, and the Beckman Institute for Advanced Science and Technology Postdoctoral Fellowship. We appreciate helpful feedback from conference participants in the Illinois Summit on Diversity in Psychological Science. This manuscript was strengthened by constructive 
comments from Lilia Cortina, Mary Rogers, Katie Lee, Meredith Wilson, and Julie Martin. We appreciate the feedback of undergraduate lab members, particularly Denise Herrera and Mariel Galvan. We are especially grateful to all of the research participants who shared their experiences.

\section{REFERENCES}

Andersson, L. M., \& Pearson, C. M. (1999). Tit for tat? The spiraling effect of incivility in the workplace. The Academy of Management Review, 24(3), 452-71.

Armstrong, M. A., \& Jovanovic, J. (2015). Starting at the crossroads: Intersectional approaches to institutionally supporting underrepresented minority women STEM faculty. Journal of Women and Minorities in Science and Engineering, 21(2), 141-157. doi: 10.1615/JWomenMinorScienEng.2015011275.

Aycock, L., Hazari, Z., Brewe, E., Clancy, K., Hodapp, T., \& Goertzen, R. (2019). Sexual harassment reported by undergraduate female physicists. Physical Review Physics Education Research. 15(1), 010121.

Bejerano, A. R., \& Bartosh, T. M. (2015). Learning masculinity: Unmasking the hidden curriculum in science, technology, engineering and mathematics courses. Journal of Women and Minorities in Science and Engineering, 21(2), 107-24.

Berdahl, J. L., Cooper, M., Glick, P., Livingston, R. W., \& Williams, J. C. (2018). Work as a masculinity contest. Journal of Social Issues, 74(3), 422-48. doi: 10.1111/josi.12289.

Berdahl, J. L., \& Moore, C. (2006). Workplace harassment: Double jeopardy for minority women. The Journal of Applied Psychology, 91(2), 426-36. doi: 10.1037/0021-9010.91.2.426.

Berenstain, N. (2016). Epistemic exploitation. Ergo, an Open Access Journal of Philosophy, 3, 569-90. doi: 10.3998/ergo.12405314.0003.022.

Braun, V., \& Clarke, V. (2006). Using thematic analysis in psychology. Qualitative Research in Psychology, 3(2), 77-101. doi: 10.1191/1478088706qp063oa.

Brody, G. H., Yu, T., Chen, E., Miller, G. E., Kogan, S. M., \& Beach, S. R. H. (2013). Is resilience only skin deep?: Rural African Americans' socioeconomic status-related risk and competence in preadolescence and psychological adjustment and allostatic load at age 19. Psychological Science, 24(7), 1285-93. doi: $10.1177 / 0956797612471954$.

Buchanan, N. T., \& Fitzgerald, L. F. (2008). Effects of racial and sexual harassment on work and the psychological well-being of African American women. Journal of Occupational Health Psychology, 13(2), 137-51. doi: 10.1037/1076-8998.13.2.137.

Buchanan, N. T., Settles, I. H., \& Woods, K. C. (2008). Comparing sexual harassment subtypes among black and white women by military rank: Double jeopardy, the Jezebel, and the cult of true womanhood. Psychology of Women Quarterly, 32(4), 347-61. doi: 10.1111/j.1471-6402.2008.00450.x.

Charmaz, K. (1995). The search for meanings_-grounded theory. In J. A. Smith, R. Harré, and L. van Langenhove (Eds.), Rethinking Methods in Psychology (pp. 27-49). London: Sage Publications.

Clance, P. R., \& Imes, S. (1978). The imposter phenomenon in high achieving women: Dynamics and therapeutic intervention. Psychotherapy Theory, Research, and Practice, 15(3), 1-8.

Clancy, K. B. H., Lee, K. M. N., Rodgers, E. M., \& Richey, C. (2017). Double jeopardy in astronomy and planetary science: Women of color face greater risks of gendered and racial harassment. Journal of Geophysical Research Planets, 122, 1-13. doi: 10.1002/2017JE005256.

Clancy, K. B. H., Nelson, R. G., Rutherford, J. N., \& Hinde, K. (2014). Survey of academic field experiences (SAFE): Trainees report harassment and assault. PLoS One, 9(7), 1-9. doi: 10.1371/journal.pone.0102172.

Cortina, L. M., Kabat-farr, D., Leskinen, E. A., Huerta, M., Magley, V. J., Kabat-farr, D., \& Leskinen, E. A. (2013). Selective incivility as modern discrimination in organizations: Evidence and impact. Journal of Management, 39(6), 1579-605. doi: 10.1177/0149206311418835.

Cortina, L. M., \& Magley, V. J. (2009). Patterns and profiles of response to incivility in the workplace. Journal of Occupational Health Psychology, 14(3), 272-88. doi: 10.1037/a0014934. 
Cortina, L. M., Magley, V. J., Williams, J. H., \& Langhout, R. D. (2001). Incivility in the workplace: Incidence and impact. Journal of Occupational Health Psychology, 6, 64-80.

Crenshaw, K. (1989). Demarginalizing the intersection of race and sex: A Black feminist critique of antidiscrimination doctrine, feminist theory, and antiracist politics. The University of Chicago Legal Forum, 1989, 139-168.

Deitch, E. A., Barsky, A., Butz, R. M., Chan, S., Brief, A. P., \& Bradley, J. C. (2003). Subtle yet significant: The existence and impact of everyday racial discrimination in the workplace. Human Relations, 56(11), 1299-324. doi: 10.1177/00187267035611002.

Fatima, S. (2017). On the edge of knowing: Microaggression and epistemic uncertainty as a woman of color. In K. Cole and H. Hassel (Eds.), Surviving sexism in academia: Strategies for feminist leadership (pp. 147-154). New York: Routledge.

Geronimus, A. T., Hicken, M., Keene, D., \& Bound, J. (2006). "Weathering" and age patterns of allostatic load scores among blacks and whites in the United States. American Journal of Public Health, 96(5), 826-33. doi: 10.2105/AJPH.2004.060749.

Gravlee, C. C. (2009). How race becomes biology: Embodiment of social inequality. American Journal of Physical Anthropology, 139(1), 47-57. doi: 10.1002/ajpa.20983.

Gunnar, M. R. (2017). Social buffering of stress in development: A career perspective. Perspectives on Psychological Science, 12(3), 355-73. doi: 10.1177/1745691616680612.

Harrell, S. P. (2000). A multidimensional conceptualization of racism-related stress: Implications for the well-being of people of color. American Journal of Orthopsychiatry, 70(1), 42-57. doi: 10.1037/ h0087722.

Hebl, M., Madera, J. M., \& King, E. (2008). Exclusion, avoidance, and social distancing. In K. Thomas (Ed.), Diversity Resistance in Organizations (pp. 127-150). New York: Lawrence Earlbaum Associates.

Hollis, L. (2017). This is why they leave you: Workplace bullying and insight to junior faculty departure. British Journal of Education, 5, 1-7.

Hutton, S., \& Gates, D. (2008). Workplace incivility and productivity losses among direct care staff. AAOHN Journal, 56(4), 168-75. doi: 10.3928/08910162-20080401-01.

Huynh, V. W. (2012). Ethnic microaggressions and the depressive and somatic symptoms of Latino and Asian American adolescents. Journal of Youth and Adolescence, 41(7), 831-46. doi: 10.1007/s10964012-9756-9.

Kabat-Farr, D., \& Cortina, L. M. (2012). Selective incivility: Gender, race, and the discriminatory workplace. In S. Fox and T. R. Lituchy (Eds.), Gender and the dysfunctional workplace (pp. 120-134). Cheltenham, UK: Edward Elgar.

Ko, L. T., Kachchaf, R. R., Hodari, A. K., \& Ong, M. (2014). Agency of women of color in physics and astronomy: Strategies for persistence and success. Journal of Women and Minorities in Science and Engineering, 20(2), 171-95. DOI: 10.1615/JWomenMinorScienEng.2014008198.

Ko, L. T., Kachchaf, R. R., Ong, M., \& Hodari, A. K. (2013). Narratives of the double bind: Intersectionality in life stories of women of color in physics, astrophysics and astronomy. Physics Education Research Conference, 1513(222), 222-5. doi: 10.1063/1.4789692.

Leskinen, E. A., Cortina, L. M., \& Kabat, D. B. (2011). Gender harassment: Broadening our understanding of sex-based harassment at work. Law and Human Behavior, 35(1), 25-39. doi: 10.1007/s10979-0109241-5.

Lewis, J. A., Mendenhall, R., Harwood, S. A., \& Browne Huntt, M. (2016). “Ain’t I a Woman?”: Perceived gendered racial microaggressions experienced by Black women. The Counseling Psychologist, 44(5), 758-80. doi: 10.1177/0011000016641193.

Lim, S., \& Cortina, L. M. (2005). Interpersonal mistreatment in the workplace: The interface and impact of general incivility and sexual harassment. The Journal of Applied Psychology, 90(3), 483-96. doi: 10.1037/0021-9010.90.3.483.

Lim, S., Cortina, L. M., \& Magley, V. J. (2008). Personal and workgroup incivility: Impact on work and health outcomes. The Journal of Applied Psychology, 93(1), 95-107. doi: 10.1037/0021-9010.93.1.95.

Volume 27, Issue 2, 2021 
Madriz, E. (2000). Focus groups in feminist research. In N. K. Denzin and Y. S. Lincoln (Eds.), Handbook of Qualitative Research (3rd ed., pp. 835-50). Thousand Oaks, CA: Sage.

Malagon, M. C., Huber, L. P., \& Velez, V. N. (2009). Our experiences, our methods: Using grounded theory to inform a critical race theory methodology. Seattle Journal of Social Justice, 8, $253-72$.

Miner-Rubino, K., \& Cortina, L. M. (2004). Working in a context of hostility toward women: Implications for employees' well-being. Journal of Occupational Health Psychology, 9(2), 107-22. doi: 10.1037/1076-8998.9.2.107.

Morgan, D. L. (1996). Focus groups. Annual Review of Sociology, 22, 129-52. doi: 10.4135/9781446212165.

Morrison, R. L. (2009). Are women tending and befriending in the workplace? Gender differences in the relationship between workplace friendships and organizational outcomes. Sex Roles, 60(1-2), 1-13. doi: 10.1007/s11199-008-9513-4.

Moss-Racusin, C. A., Dovidio, J. F., Brescoll, V. L., Graham, M. J., \& Handelsman, J. (2012). Science faculty's subtle gender biases favor male students. Proceedings of the National Academy of Sciences, 109(41), 16474-9. doi: 10.1073/pnas.1211286109.

National Academy of Sciences, Engineering, and Medicine. (2018). Sexual Harassment of Women: Climate Culture, and Consequence in Academic Sciences, Engineering, and Medicine. Washington, DC: The National Academies Press.

National Science Board. (2012). Science and engineering indicators 2012. Arlington VA: National Science Foundation (NSB 12-01).

Navarro, T., Williams, B., \& Ahmad, A. (2013). Sitting at the kitchen table: Fieldnotes from women of color in anthropology: Introduction: Gender, race, and anthropological practice. Cultural Anthropology, 28(3), 443-63. doi: 10.1111/cuan.12013.

Nelson, R. G., Rutherford, J. N., Hinde, K., \& Clancy, K. B. H. (2017). Signaling safety: Characterizing fieldwork experiences and their implications for career trajectories. American Anthropologist, 119(4), 710-22. doi: 10.1111/aman.12929.

Newman, M. E. J. (2001). The structure of scientific collaboration networks. Proceedings of the National Academy of Sciences of the United States of America, 98(2), 404-409. doi: 10.1073/pnas.021544898.

Rabiee, F. (2004). Focus-group interview and data analysis. Proceedings of the Nutrition Society, 63(4), 655-60. doi: 10.1079/PNS2004399.

Rios, D., \& Stewart, A. J. (2015). Insider and outsider-within standpoints: The experiences of diverse faculty in science and engineering fields. Journal of Women and Minorities in Science and Engineering, 21(4), 295-322. doi: 10.1615/JWomenMinorScienEng.2015010375.

Riskin, A., Erez, A., Foulk, T. A., Kugelman, A., Gover, A., Shoris, I., Riskin, K.S., \& Bamberger, P. A. (2015). The impact of rudeness on medical team performance: A randomized trial. Pediatrics, 136(3), 487-95. doi: 10.1542/peds.2015-1385.

Roshanravan, S. M. (2009). Passing-as-if: Model-minority subjectivity and women of color identification. Meridians: Feminism, Race, Transnationalism, 10(1), 1-31. doi: 10.2979/mer.2009.10.1.1.

Schneider, K. T., Hitlan, R. T., \& Radhakrishnan, P. (2000). An examination of the nature and correlates of ethnic harassment experiences in multiple contexts. Journal of Applied Psychology, 85(1), 3-12. doi: 10.1037//0021-9010.85.1.3.

Sellers, R. M., Caldwell, C. H., Schmeelk-Cone, K. H., \& Zimmerman, M. A. (2003). Racial identity, racial discrimination, perceived stress, and psychological distress among African American young adults. Journal of Health and Social Behavior, 44(3), 302-17. doi: 10.2307/1519781.

Settles, I. H., Cortina, L. M., Malley, J., \& Stewart, A. J. (2006). The climate for women in academic science: The good, the bad, and the changeable. Psychology of Women Quarterly, 30(1), 47-58. doi: 10.1111/j.1471-6402.2006.00261.x.

Shupe, E. I., Cortina, L. M., Ramos, A., Fitzgerald, L. F., \& Salisbury, J. (2002). The incidence and outcomes of sexual harassment among hispanic and non-hispanic white women: A comparison across levels of cultural affiliation. Psychology of Women Quarterly, 26(4), 298-308. doi: 10.1111/1471-6402.t01-2-00069. 
Spanierman, L. B., \& Smith, L. (2017). Roles and responsibilities of white allies: Implications for research, teaching, and practice. The Counseling Psychologist, 45(5), 606-17. doi: 10.1177/0011000017717712.

Sue, D. W., Capodilupo, C. M., Torino, G. C., Bucceri, J. M., Holder, A. M. B., Nadal, K. L., \& Esquilin, M. (2007). Racial microaggressions in everyday life: Implications for clinical practice. American Psychologist, 62(4), 271-286. doi: 10.1037/0003-066X.62.4.271.

Tatum, B. D. (2017). Why are all the black kids sitting together in the cafeteria? And other conversations about race (Twentieth anniversary edition). New York: Basic Books.

Wilkinson, S. (1998). Focus groups in feminist research: Power, interaction, and the co-construction of meaning. Women's Studies International Forum, 21(1), 111-25.

Volume 27, Issue 2, 2021 
